\title{
Correlating the diversity awareness within the organizations of Bangladesh in the era of industry 4.0-Human resource perspective
}

\author{
Mohammed Kamruzzaman ${ }^{1}$, Sunan Islam² \\ ${ }^{1}$ Assistant Professor, International University of Business Agriculture and Technology \\ ${ }^{2}$ PhD Researcher, Putra Business School, Universiti Putra Malaysia
}

\begin{abstract}
Organizations strategically adopt various diversity and inclusion initiatives to encourage the diversity approach of a diverse workforce. Many social science authors and HRM scholars mostly focused on studying diversity models in societal/organizational outcomes. This paper aims to study the correlations of mainly four HR practices in Bangladeshi origin organizations, i.e., employee engagement, diversity training, diversity alignment, and mutual respect, with diversity awareness of diverse workforce working in the organizations. Data was collected through a questionnaire survey of a sample size of 218 employees (108 males, 110 females) from Bangladeshi origin organizations. The statistical tools, such as reliability tests, multiple correlations, multiple regressions, ANOVA, and hypotheses tests, were used for data analysis and interpretations. This research finding showed that employee engagement, diversity training, and diversity alignment is significant to diversity awareness except for mutual respect. The present study contributes to the HRM literature by proposing a conceptual framework of how these four independent variables react to diversity awareness. The study highlights the importance of diversity awareness by diverse employees as a competitive advantage to make multi-cultural firms in the era of industry 4.0.
\end{abstract}

Keywords: Employee diversity, employee engagement, diversity training, diversity alignment, mutual respect.

\section{INTRODUCTION}

$\mathrm{I}^{\mathrm{n}}$ n recent years, several Bangladeshi origin firms have been rapidly adopting one of the most emerging HR buzzwords, i.e., diversity and inclusion practices. Bangladesh symbolizes diversity in unity, and it also reflects in its people. Usually, these diverse reflections witness in their social, political, cultural, spiritual beliefs, linguistic, ideological, customary festivals, and public life. Although diversity has been a critical characteristic of Bangladesh society, the broader view of diversity is yet fully evident in the behavior of employees working in Bangladeshi origin firms. Encouraging the awareness of diversity and inclusion practices among employees has become an emerging HR concern for Bangladesh based organizations. Large numbers of studies published in Bangladesh which discussed diversity practices in organizations (e.g., Dameron \& Joffre, 2007; Maxwell, Blair, \& McDougall, 2001; Nishii \& Özbilgin, 2007; Sippola \& Smale, 2007; Soni, 2000; Subeliani \& Tsogas, 2005). However, most of these studies have often focused on western countries, using survey studies or case studies on diversity practices at various firms (Cooke \& Saini, 2010). Bangladeshi origin firms have initiated to adopt diversity management as an emerging HRM practice on the rich ground in recent years (Cooke \& Saini, 2010). However, studies do not cover the internal organizational intricacy in the curse of formulating and implementing diversity \& inclusion (D\&I) policy from the perspectives of diverse groups of workforces (Cooke \& Saini, 2010).

Over the years, several researchers have presented large numbers of theories and research articles on diversity awareness. Bertrand and Mullainathan (2004) extended social cognitive theory (Bandura, 1960) in shortlisting of curriculum vitae (CV) of job applicants based on race, gender, age, and person's surname. This theory recommends that a person's classification links to the stereotype approach, which may lead to the over extrapolation of a person's characteristics (Birkelund, Johannessen, Rasmussen, \& Rogstad, 2020). In connection to employment opportunity, the overgeneralization and stereotype approach encourages bias and discrimination and may hamper the hiring decisions (Bertrand \& Mullainathan, 2004). In the perspective of social cognitive theory, people use large amounts of available and noticeable information such as name, sex, gender, to classify a person (Bussey \& Bandura, 1984; Huston, 1983). Thus, it can lead to an instinctive judgment of a particular person without knowing his/her original characteristics (Rooth, 2010). This gap in identifying a person using the social-cognitive approach limits the reliability of valuing diversity awareness.

Several research scholars studied the contribution of social identity theory in the context of theoretical development on diversity awareness that what type of social environment emerges when the diverse group members interact (Tajfel \& Turner, 1979). These studies aimed to explore whether the social identity concept supports diversity awareness or not? Many social science scholars further reported that conceptualizing the diversity approach in the context of the social identity model could be unfavorable (Tajfel, 1974; Tajfel \& Turner, 1985). The social identity theory suggests that people's socialization depends on the appearance of similar and dissimilar characteristics, attitudes, and behaviors (Tajfel \& Turner, 1985). It means that people having similarities can belong to one group (in-group), and another 
group is an out-group, not the members of the in-group (Billig $\&$ Tajfel, 1973). Such categorization based on the outlook of the members encourages stereotyped behaviors. It can create an environment of favoritism, nepotism, and criticism among the group members (Campbell, 1967). Thus, diversity perception deviates from achieving its objectives.

Researchers have given more attention to the organizational outcome, either useful or harmful, in describing diversity awareness (e.g., Miller, Burke \& Glick, 1998; Horwitz \& Horwitz, 2007; Watson, Kumar, \& Michaelson, 1993; Tsui, Egan, \& O'Reilly, 1992). Bantel and Jackson (1989) found that more diversity awareness exists in organizations witnessed a higher level of innovation, creativity, and an improved working system, leading to higher productivity. Several works of literature supported that diversity promotes innovation (Kutch \& Kutch, 2019; Cox \& Blake, 1995; Kundu, 2003; Wambui et al., 2013), creativity (Friedman, Leverton, \& Friedman, 2015; Kaufman et al., 2010; Cox \& Blake, 1995) and increases problem-solving ability (Hoffman \& Maier, 1961; Cox \& Blake, 1995) in organizations. These works of literature recommend that having diverse talent in organizations encourages generating different opinions, ideas, and innovative suggestions, which, in turn, helps find the best solutions.

However, other scholars showed the inverse relationship between diversity awareness and organizational outcome. O'Reilly, Snyder, and Boothe (1993) have contended that a diversity approach results in a lower level of interaction, collaboration, and communication, which affect the working system and lead to adverse organizational performance. Some scholars argue that diversity could be an instrument to create clashes among team members because differences in opinion occur naturally and may cause a group to disengage from the work (Watson, Kumar, \& Michaelson, 1993). In research fraternity, this is a big argument whether diversity awareness has a positive or negative outcome in an organizational context. With authors' knowledge, no empirical research found which provide consistent evidence that diversity awareness has either favorable or unfavorable outcome (e.g., Bantel \& Jackson, 1989; Glick, Miller, \& Huber, 1993; Jackson et al., 1991; Michel \& Hambrick, 1992; Murray, 1989; O'Reilly et al., 1993; Smith et al., 1994; Wiersema \& Bantel, 1992, 1993). Miller, Burke, and Glick (1998) have mainly discussed two types of diversity, i.e., demographic (e.g., race, age, gender) and cognitive (e.g., knowledge, creativity, innovation, information, skills) diversity. They argued that for non-existent of such contradictory evidencebased organizational outcomes, researchers have probably emphasized demographic diversity more than cognitive diversity. Theoretically, no direct association reported between demographic diversity and firm performance, but it indirectly affects (Glick et al., 1993). Further, an empirically evidence-based research study proved that there is an inconsistent relationship between diversity awareness and organizational outcome (Miller, Burke \& Glick, 1998).
Literature supported that diversity may cause individuals behavioral change in the context of interpersonal relationships (Reich \& Hershcovis, 2011; Chattopdhyay, George, \& Shulman, 2008; Baumeister \& Leary, 1995; Harrison, Price, \& Bell, 1998). Some researchers showed that diversity led dissension among team members, which in turn decreased the retention rate of executives in organizations (Tsui, Egan, \& O'Reilly, 1992; Horwitz \& Horwitz, 2007; Cox \& Blake, 1991). Organizations include a group of diverse people (Patrick \& Kumar, 2012). The absence of mutual respect among themselves at the workplace may lead to a higher resignation rate (Byrne, 1971; Tsui, Egan, \& O'Reilly, 1992). Byrne's (1971) similarity attraction theory is one of the initial theoretical concepts that emerged to address the likeness paradigm. Likeness pattern may be in the form of attitude, work-related, social, and physical. Byrne (1971) defined the application of this theory to address diversity approach in the organizational context and showed that people first observe and give value to others with whom they can share similar attributes. Like other diversity theories, this also limits the broader view of diversity because it suggests that undesirable interpersonal relationship could emerge in groups. All these theories and scholarly research studies discussed diversity awareness in dimensions of categorization, identification, innovation, creativity, problem-solving ability, relational association, and organizational performance. Moreover, diversity is a business strategy (Cascio, 1998; Gomez-Mejia, 2010; Thomas, 2004), and organizations invest in executing it, predicting higher returns.

For two decades, diversity management has been a critical objective for human resource management (Kundu, Bansal, \& Chawla, 2015). In the organizational context, human resource management (HRM) is seen as a key process owner to manage diversity models amidst a diverse workforce associated with firms (Cascio, 1998; Babalola \& Marques, 2013; Kreitz, 2008). It is evident from pieces of literature and case studies that HRM deals directly with various aspects of diversity management in organizations (Ulrich, 1998; Babalola \& Marques, 2013; Alcazar et al., 2013; Shen et al., 2009; Skinner, 1981; Dobbin \& Kalev, 2016; Krentz, 2019). The diverse workforce is a strength for the organization (Cascio, 1998; Gomez-Mejia, 2010). To attract, recruit, develop, manage, and retain diverse talents is one of the crucial aims of HRM (Cascio, 1998; Kundu, Bansal, \& Chawla, 2015). HR practitioners implement various diversity practices to encourage the workforce to be a consistent partner for achieving the organizational goals irrespective of differences amidst themselves (Gallo, 2011). Employee engagement (Ilgen \& Pulakos, 1999; Howard, 1995; Sun \& Bunchapattanasakda, 2019; National Research Council, 1999; Cappelli et al., 1997; Cappelli, 1999) and employee training (Schneider, White, \& Paul, 1998; Cappelli et al., 1997; Jehanzeb \& Bashir, 2013; Colarelli \& Montei, 1996; Becker, 1993; Goldstein \& Ford, 2002; Bartlett, 2001) is a strategic HR practice. In today's organizational context, HR uses employee engagement activity to create synergy amid the 
workforce by building a diverse team for the accomplishment of certain objectives in organizations. Further, diversity training has been a popular HR tool to sensitize workforce towards various cultural, demographic and cognitive differences in organizations (Alhejji et al., 2016; Qin, Muenjohn, \& Chhetri, 2013; Schmidt, Githens, Rocco, \& Kormanik, 2012; Boekhorst, 2015; Brooks \& Clunis, 2007; Curtis \& Dreachslin, 2008). Promoting inclusive culture in organizations is one of the key priorities of top leadership in today's corporate world (Mazur, 2014; Pless \& Maak, 2004, p.129). HR is considered as a change agent (Ulrich, 1998) to build an environment of inclusive organizational culture. The task of policy formulation to implement the diversity model entrust to HR leadership (Patrick \& Kumar, 2012; Abidi et al., 2017). The key focus of diversity inclusion is to align the diverse workforce with organizational goals, core values, culture, traits, norms, and philosophy (D'Netto \& Sohal, 1999; Thomas, 1990; Cox, 1993; Solomon, 2001; Sabharwal, 2014; Tamunomiebi \& Dienye, 2019). Literature showed that diversity inculcates a culture of respect for self and others (Nyanchama \& Muathe, 2018; Jay, 2003; Fullinwder, 1996). HR helps build a culture of individual and mutual respect, which, in turn, a diverse workforce feels honored, motivated, and committed. Previous literature on diversity awareness mostly discussed organizational outcomes on account of the implementation of various diversity practices. Several studies are available on the diversity awareness model. Still, most of these studies probably focused on managerial, executive and women's diversity and their perception towards understanding others (e.g., Miller, Burke, \& Glick, 1998; Smilansky, 2012; Roselberg, 2009; Ogbolu, Scrandis \& Fitzpatrick, 2017; Bader, Kemper, \& Froese, 2019; Sarhan \& Ntim, 2018; Zhu \& Shen, 2016; Athanasopoulou et al., 2018; Lee \& James, 2007). Many researchers have focused on studying the value of diversity at the top leadership level in organizations (Rahman, 2019; Back, 1998; Gentry et al., 2014; Okoro, 2012; Chuang, 2013). The present study identifies mainly four key HR practices, i.e., employee engagement, diversity training, diversity alignment (inclusion), and mutual respect. The literature says that HR practitioners design policy, procedure, structure, and methods to implement these HR practices to promote diversity awareness, which builds an inclusive culture in organizations (Findler, 2007; Downey et al., 2015). In other words, the ultimate purpose of a diversity approach is to improve organizational outcomes and to build a broad organizational culture. Theoretically, I found that researchers have not given much attention to studying the correlations of these HR practices with diversity awareness, particularly covering employees' diversity perception.

Numerous studies and literature showed that if cultural change initiative is not associated with the employees, then the leadership's efforts are meaningless (Hayes, 1999; Jackson et al., 1992). Similarly, implementing diversity practices in organizations is successful, unless a critical stakeholder 'employee' is aware of it. Mankidy (1995) found that the various interventions for intercultural awareness should cascade down to the shop floor workforce for their adequate cognizance, responsiveness, and acceptance. Diversity includes a group of people from various backgrounds working together in an organizational setting (Kundu, 2003). In the present corporate work culture, having a diverse workforce is a competitive advantage (Cox \& Blake, 1991; Jackson et al., 1992; Kundu, 2003). The top leadership is now more focused on adopting strategic diversity practices in organizations (Kundu, Bansal, \& Chawla, 2015). The scholarly articles on diverse employee's perceptions towards diversity awareness in the context of Bangladeshi origin firms are not much known, and probably researchers have given less attention to include the various background employees in the research study. The present paper focuses on studying the employee's insights on diversity and connecting their diversity awareness with the four identified variables used in this study. Based on the identification of a gap in diversity cognizance of employees, this paper suggests a theoretical model (please see figure-1) aiming to correlate the diversity awareness (dependent variable) with four independent variables, i.e., employee engagement, diversity training, diversity alignment, and mutual respect. The study also discovers the degree of intercorrelations among four independent variables. I used a theoretical framework as sketched below in this study (please see figure-1).

Figure 1-Proposed conceptual framework

Figure 1-Proposed conceptual framework

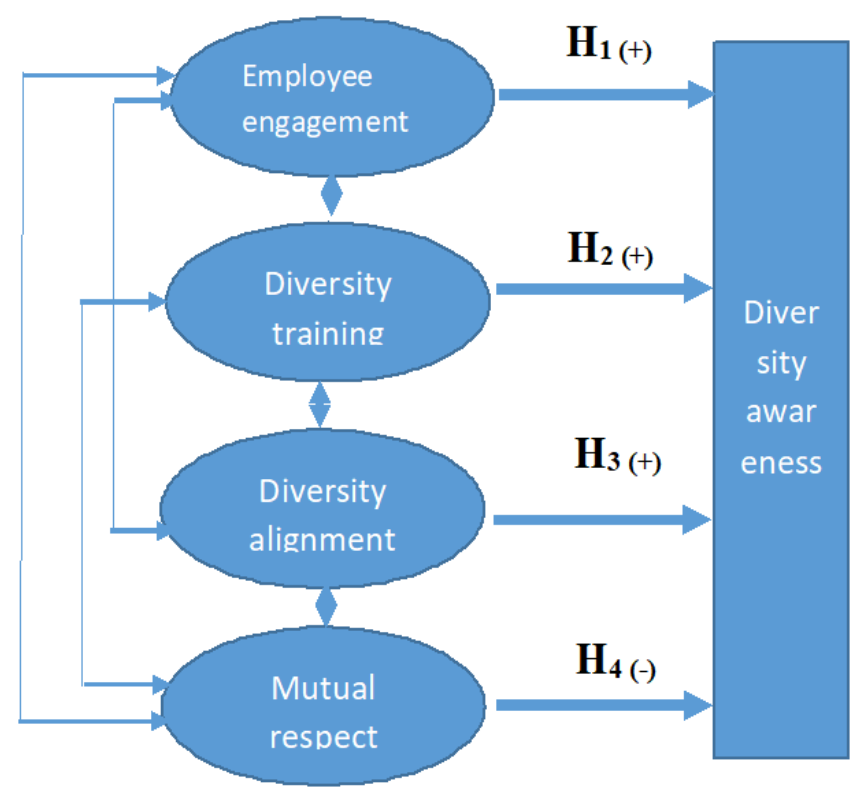

Note: (+) indicates a positive relationship between the constructs. (-) Indicates a negative correlation.

\section{LITERATURE REVIEW}

This chapter presents a review of the literature on the measured variables defined in the present study. 


\section{Diversity awareness}

The diversity concept first originated from US companies in the late 1980s (Shen et al., 2009; Meena \& Vanka, 2013). Literary, diversity signifies to the differences. The word "diversity" denotes several groups of personal variances, as well as differences in a large group of people, values, gender, religion, dialect, culture, custom, and age (Hopkins, 1997); literacy level, competencies and abilities, a domain area proficiency, administration procedures, occupation, paternal position, marital position, household contextual, professional interests, career ambitions, topographical differences (Diamante, Reid, \& Giglio, 1995); societal position, physical and psychological settings (Thomas, 1994); a way of communication (Van Eron, 1995); including behavioral characteristics, functioning styles, and organizational departments. In one sentence, diversity simply refers to the many different ways people in society/organizations differ (Day, 1995). Awareness refers to acquiring the idea, perception, and information on the differences that increasingly become a popular topic in today's corporate world. The human diversity means differences among people. That is why increasing diversity awareness has become a primary concern and an emerging HR practice in many organizations. For the last two decades, diversity has become the company's driving gear to attract a versatile workforce (Kundu, Bansal, \& Chawla, 2015). The company's diversity practices ensure the availability of a diverse workforce that ultimately builds up a mixed culture. Working in such a culture brings a broader range of brains, ideas, and opinions. Companies move one step ahead by adopting it as a corporate culture and strategy for the global reach of business expansion (Cascio, 1998).

Researchers have usually attempted to answer how strategic diversity practices have helped global organizations increase financial performance and gain a competitive advantage (Gordon, 1995; Hayles \& Russell, 1997; Eron, 1995). Their findings reveal that there are several reasons diversity practices have multiplied the growth trajectory of business across geographical locations. The concept of diversity management has reimagined and reshaped the organizational culture, norms, traits, and behaviors (Jacqueline et al., 1999). Diversity refers more than race and gender in today's corporate context. Today organizations create an environment to promote the diverse workforce where different voices, skills, knowledge, and abilities are encouraged for innovation and creativity (Hayles \& Russell, 1997).

Numerous authors have reported on the factors which affect the diversity awareness of the workforce in the organization. Cavaleros, Vuuren, \& Visser (2002) found that diversity training program is a popular tool to increase diversity awareness. According to Intergroup Contact Theory, Allport (1958) determined that human to human interactive contact is one of the most effective tools to reduce bias among varied cultural groups. To reduce prejudice, Allport (1958) suggested that the collaborating members should have equal status, a common goal, and there should be no rivalry between the groups. Intergroup contact refers to face-to-face interactions between members of defined cultural groups (Pettigrew \& Tropp, 2006). Researchers use the existence of mutual respect to a common attribute among the diverse workforce as an indicator to measure the diversity awareness (Harrison \& Klein, 2007, p. 1200) amid heterogeneity, variation, or dissimilarity of members (Harrison \& Klein, 2007). To align the varied workforce with diversity policy and practices' objectives is critical in creating diversity awareness in the organization (Wildavsky, 1991; Kendra \& Wachtendorf, 2003).

In summary, the literature showed that managing diversity effectively leads to a proactive and positive approach (Babalola \& Marques, 2013) envisioned to manage a heterogeneous workforce (Cascio, 1998) in such a manner so that the potential advantages of diversity maximize while its potential disadvantages minimize (Cox, 1993). Bangladeshi organizations have adopted various diversity practices as a corporate strategy to ensure social, economic, legal, and political gain to the extent (Wambui et al., 2013). Bangladeshi firms have started leveraging diversity (Meena \& Vanka, 2013) to attract the workforce from diverse races, gender, creed, groups, age, and religions across the nation.

\section{Employee engagement}

Employee engagement has been one of the most burning HR practices in corporate circles for several years (Macey \& Schneider, 2008; Siddhanta \& Roy, 2010). Several authors, academicians, practitioners, and researchers have presented papers on this buzzword. In the 1990s, Kahn coined the term engagement and explained that people could make influence physically, cognitively, and emotionally through their varying degrees of identities at the workplace. The book 'First break all the rules: what the world's greatest managers do differently' written by Buckingham and Coffman (1999) promoted the word 'employee engagement' to become popular and widespread in the corporate world. Mone et al. (2011, p. 206) defined employee engagement as an employees' wisdom of drive, determination, commitment, and orientation revealed to others by demonstrating individual initiative, flexibility, action, and perseverance focused on the achievement of an organization's goals. Gebauer and Lowman (2009) defined employee engagement as having a profound and broad association with the organization. Consequently, it boosts up will power to go above and beyond contribute to organizational success.

According to the Contact Hypothesis Model (Cavaleros, Vuuren, \& Visser, 2002), engaging a diverse group increases the sense of belongingness and minimizes prejudice at the workplace. Numerous studies and literature have proved that a productive engagement activity among diverse workforce attracts customers and makes the organization a wide-ranging customer-friendly entity (Wentling \& Palma-Rivas, 2000). Hayles and Russell (1997) found that in an organization where 
employee engagement among the varied workforce is more, have more intercultural awareness than in an organization where less engagement exists. Starbucks is a renowned and worldwide familiar brand in the market. The business ethics and compliance of Starbucks (2011) narrates,

\section{(..) actively develops an environment that is inclusive of all cultures and their unique abilities, strengths, and differences and promotes diversity as a strategic and competitive business advantage for the company (Morais et al., 2014, p. 41).}

Starbucks believes that active participation and engagement is essential to gain cultural competence which increases diversity awareness. Eventually, the senior leadership should demonstrate such commitment, which in turn inspires the behavior of varied workforce across the organization (Elder et al., 2014; Hinkin \& Tracey, 2010). A committed and engaged workforce is always prepared to honor a diverse opinion proposed by a diverse workforce. Paying attention such differences itself resembles a presence of diversity awareness in the organization.

Hypothesis: Diversity awareness vs. employee engagement (HI)

Ho: There is no significant relationship between diversity awareness and employee engagement.

H1: There is a significant relationship between diversity awareness and employee engagement.

\section{Diversity training}

Training is a developing tool to increase skill, knowledge, and ability. It refers to an organized method of acquiring knowledge and expertise, which improves learning in individual, group, and organizational levels (Goldstein \& Ford, 2002; Khawaja \& Nadeem, 2013). Chiaburu and Teklab (2005) defined training as the systematic and strategic intervention intended to increase the factors of the work performance of an individual at the workplace. Training includes the planned, organized, and structured developmental initiatives and activities, which results in improved skills, essential to accomplish work effectively and efficiently (Gordon, 1992). Training related activities act as a catalyst to change individual behavior and attitude that improve the probability of achieving cultural transformation and business goals in an organization (Truitt, 2011). The primary aim of diversity training is to transform employees' attitudes, knowledge, and skills to improve their behavior towards adaptability to work with diverse workforces at the workplace (Yap et al., 2010). According to Laird (1985), training is a kind of practice, curriculum, or program that ensures that individuals acquire new, innovative, and predetermined behaviors. Similarly, the well-structured training initiative on diversity awareness aims to change individuals' behavior (Thomas, 1994) to eradicate discrimination, bias, and favoritism (Cavaleros, Vuuren, \& Visser, 2002). The systematic training on diversity and inclusion is a strategic action to increase diversity awareness among the diverse workforce working in the organization today.

Usually, diversity training aims to make people understand their personal bias (Thomas, 1994), which significantly affects the consequences and the degree to which behavior is changed (Cavaleros, Vuuren, \& Visser, 2002). Patterson (1986) concluded in his research that behavior is characterized and affected by numerous factors like individuals' traits, norms, characteristics, perception, value system, backgrounds, intuition, including biological reactions, emotional responses, relational collaboration, social connection, and attributes. Hence, diversity awareness training's primary objective is to influence an individual's perception, probably resulting in the transformation of his/her behavior (Cavaleros, Vuuren, \& Visser, 2002). Most organizations have agreed that it is necessary to have an inclusive training program on diversity awareness yet not indispensable to business, are now understanding the importance, and have started to admit and recognize its value addition (Diamante et al., 1995). These organizations have documented well-structured policies and strategies to promote diversity \& inclusion (D\&I). The diversity training program is now preferably designed to incorporate personal differences to make diverse employees more conscious of a multi-cultural workplace environment and its implications, including contributing towards the building of affirmative and positive organizational culture (Diamante et al., 1995). Numerous studies have found that diversity training is a primary tool to boost diversity awareness among diverse employees (Roberson et al., 2001; Wentling \& Palma-Rivas, 2000). However, the training initiative alone cannot address all of the factors contributing to diversity awareness. Still, it is essential to prepare employees' mindsets and attitudes towards acquiring a glimpse of diversity perception to a more considerable extent.

Hypothesis: Diversity awareness vs. diversity training (H2)

Ho: There is no significant relationship between diversity awareness and diversity training.

H1: There is a significant relationship between diversity awareness and diversity training.

\section{Diversity alignment}

Diversity and inclusion (alignment) often used interchangeably. However, for this review, diversity signifies the gamut of human similarities and differences. Diversity is about people. On the other hand, alignment is to make an inclusive organization. Inclusion is about aligning people with organizational goals and objectives (Woods, 2002). Inclusion has been defined distinctly by numerous authors. Pelled, Ledford, and Mohrman (1999, p. 1014) defined inclusion as a welcome gesture for an individual by group members in a working system. Roberson (2006, p. 217) argued that inclusion refers to removing obstacles to the full participation and contribution of employees in organizations. Miller (1998, p. 151) similarly labeled inclusion as the degree to which 
diverse individuals are allowed to participate and enabled them to contribute fully. In a nutshell, diversity alignment is to operationalize diversity policies and strategies with other internal people strategy. Organizations construct prospect, contact, collaboration, message, and system to achieve diversity goals (Woods, 2002). The research proved that diversity inclusion is a substantial competitive advantage for an organization and is useful for creating intercultural awareness among diverse workforces (Praveenadevi \& Girimurugan, 2019).

As evident from the literature, diversity inclusion helps an organization build a collaborative culture, which in turn, diverse workforce work together across verticals and hierarchies to solve the problems (Woods, 2002). This collective approach leads towards the removal of individual interest; instead, intergroup members work to synchronize the organization's inclusive growth (Woods, 2002). According to Imhoff and Erb (2008), when a diverse workforce's unique capability aligns with the organizational strategic goals, they are more inclined and committed to demonstrating exceptional elements to accomplish goals regardless of social, spiritual, and political differences. The research has also revealed that when an apparent purpose confronts, people from unique backgrounds prefer to work in a team with honoring others and overlook their ethos and philosophy ((Lepak \& Snell, 1999). In conclusion, I summarize that diversity inclusion creates an environment of awareness of self and others. It provides individuals with an opportunity to develop a broader aspect of consciousness, relational perception, leadership skills, a broad mind, and curious to know others (Woods, 2002).

Hypothesis: Diversity awareness vs. diversity alignment (H3)

Ho: There is no significant relationship between diversity awareness and diversity alignment.

H1: There is a significant relationship between diversity awareness and diversity alignment.

\section{Mutual Respect}

Mutual respect is irreplaceable for cultivating work relationships regardless of individual personality, irrespective of one's family background and lifestyle (Ferguson \& Page, 2003). The critical factors of mutual respect are motivation, cooperation, and encouragement (Ferguson \& Page, 2003). Mainly three words often demonstrate respect for oneself and others. Seeming motivated oneself when one is discouraged, cooperation involves mutual understanding, and respect for others reveal by encouraging others when they are discouraged regardless of the differences physically, emotionally, cognitively, and spiritually (Ferguson \& Page, 2003). Respect is an essential characteristic of an individual and its relations with others, and, probably, it is a substantial aspect of the association between groups of individuals (Grady, 2017). Respect defines as the reverence demonstrated by an individual to others; however, the concept of reverence is still the attention of sufficient theoretical argument (Darwall, 1977, 2006). Reverence may probably be paid either on account of social rules or the terrible behavior of others; yet, the whole popular argument emphasizes the center of admiration on a person's self-esteem (Kant, 1855; Darwall, 2006). Hoban (1977, p. 232) defined respect as sincerity to others, regard for others to maintain human dignity and level of quality of their performance.

To the best of the authors' knowledge, not much research supports finding the relationship between mutual respect and diversity awareness. However, I reviewed whatever available resources to understand the relationship between mutual respect and diversity awareness. The philosophy of diversity directs to recognize that each individual is unique and identifying individual uniqueness and dissimilarities (Patrick \& Kumar, 2012). If mutual respect exhibits amid diverse groups of workforces irrespective of differences in culture, qualities, and experiences, then it portrays that they are aware of diversity notions (Patrick \& Kumar, 2012). Showing respect to all humanity variances and likenesses by a wideranging group of members is a reliable indicator of diversity awareness (Patrick \& Kumar, 2012). The idea of diversity includes acceptance and reverence.

\section{Hypothesis: Diversity awareness vs. mutual respect (H4)}

Ho: There is no significant relationship between diversity awareness and mutual respect.

H1: There is a significant relationship between diversity awareness and mutual respect.

\section{RESEARCH METHODOLOGY}

This study adopts a quantitative approach to outline the research direction and method for collecting primary data. Neuman (2006) showed that the quantitative method could measure the unbiased evidence using variables where data is detached from the concept, numerically analyzed, and highlighted with consistency. I used a quantitative method to develop hypotheses comprised of all the variables to test the questionnaire statement by statistical technique empirically. For data collection, I used ten numbers of survey questionnaires, which consist of 2 questions for every five defined variables. The Likert scale of 5-points, i.e., strongly disagree (1) to strongly agree (5), was used for scaling of variables and distributed to the respondents for filling up the questionnaires. This section introduces the data collection method used to gather information from the target respondents utilizing a set of questions in a scale rating manner. I used MS Excel (2016 version) program to process the empirical analysis and interpretations.

\section{Data collection method}

I collected primary data to test the formulated hypotheses empirically, hence proving the research hypotheses. The study covers employees from four big sizes of Bangladeshi origin firms, namely PRAN-RFL group, ACI group, NAVANA 
group and SQUARE group. A total of 218 employees (108 males, 110 females) from all these firms interviewed through a set of questionnaires. For each of the five identified variables, two numbers of questions asked to the sample respondents. I took an average response score of two questions against each defined variable for data analysis.

\section{Sampling design}

Target respondents are considered a particular group of people or objects to whom the researcher can ask questions or observe to gather necessary data and information (Hair \& Bush, 2006). My target respondents are diverse employees working at these identified four big-sized Bangladeshi origin firms in this research.

\section{Sampling frame \& sampling location}

The sampling frame refers to a set of source materials from which the sample is chosen (Hong et al., 2012). The definition also integrates the sampling frame's objective, which is to provide a means for selecting the specific members of the target respondents to interview in the survey (Turner, 2003). However, the sampling location is where research occurs or/and a place where information is acquired. Further, few respondents from these firms were requested virtually to fill up the questionnaires. In this research, diverse employees are respondents who work in four various Bangladeshi origin companies.

\section{Sampling technique}

According to Malhotra (2007), non-probability sampling is less expensive, less time consuming, and requires only little sampling skills. Therefore, a convenience sampling technique was adopted to select the samples. Moreover, I decided on the sample units based on professional contact, personal understanding, and convenience. The targeted respondents were easily approachable to obtain the sources of materials and information required for this research.

\section{Research instrument}

I used questionnaires as a research instrument in this study. The fundamental purpose of using a questionnaire survey is to collect direct replies and feedback from the targeted respondents in lesser time and a more natural way.

\section{Questionnaire design}

The closed-ended questionnaires were structured and used to ease the method of examining the data obtained from the respondents in this research. Consequently, the information collected from the target respondents increased the speed and accuracy of reporting of data, including more comparable. I designed questionnaires based on a review of the literature on diversity management practices. The survey questionnaires were validated from the previous research papers conducted by other researchers and slightly modified appropriately to the current study. Subsequently, I also studied organizational perspectives while constructing questionnaires to conduct the survey. The questionnaires were developed in simple English language to increase respondent's understanding and clarity.

Five options provided for each questionnaire prepared on the broad parameters of diversity awareness, employee engagement, diversity training, diversity alignment, and mutual respect. The questionnaire statement was distributed to the respondents to choose one option. I collected information by distributing questionnaires, both offline and online. For online surveys, I floated questions in Google sheet, and the link sent to the respondent's email ID. I quantified the survey responses into numerical value based on the degree of importance of reactions, i.e., strongly disagree, disagree, neutral, agree, and strongly agree. They were assigned a numerical value to $1,2,3,4$, and 5. I took a Likert scale 5points for scale measurement, which tends to give high reliability. According to Chomeya (2010), it allows the respondents to select the central point in a situation if the respondents replied the questions randomly because they might contemplate that responding to the central location didn't influence any disadvantage to the interpretation of data analysis.

\section{DATA ANALYSIS AND INTERPRETATIONS}

\section{Reliability test}

I developed multiple-item instruments with Likert-type scaling for reliability test. Reliability defines as consistency in results from repetitive measurements (Glasser et al., 1990). According to Thanasegaran (2009), reliability is the degree to which measures are free from error and yield consistent results. In a nutshell, reliability is the uniformity of a measurement technique on a determining instrument. The measurement is assumed consistent if the test technique invariably yields a similar outcome or score.

Table 1-ANOVA: Two-factor without replication Model summary

\begin{tabular}{|c|c|c|c|c|c|c|}
\hline $\begin{array}{c}\text { Source } \\
\text { of } \\
\text { Variation }\end{array}$ & SS & df & MS & F & P-value & $\begin{array}{c}\text { F } \\
\text { crit. }\end{array}$ \\
\hline Rows & 664.614 & 217 & 3.063 & 2.812 & $\begin{array}{c}2.2695 \mathrm{E}- \\
26\end{array}$ & 1.187 \\
\hline Columns & 64.701 & 4 & 16.175 & 14.853 & $\begin{array}{c}9.5719 \mathrm{E}- \\
12\end{array}$ & 2.382 \\
\hline Error & 945.299 & 868 & 1.089 & & & \\
\hline Total & 1674.614 & 1089 & & & & \\
\hline
\end{tabular}

Cronbach's Alpha coefficient $=1-($ MS Error/MS Rows $)$

$$
\begin{aligned}
& =1-(1.089 / 3.063) \\
& =1-0.36 \\
& =0.64
\end{aligned}
$$

Table 1 shows the output summary of 'ANOVA: Two-factor without replication' test. I examined the sample data for ten numbers of items to get the Cronbach's alpha $(\alpha)$ reliability coefficient using MS Excel-2016, and results were put into the 
formula as illustrated above (please see table-1). A Cronbach's alpha reliability coefficient is a determining factor to test the internal consistency and homogeneity of sample data collected by the researcher (Gliem \& Gliem, 2003). George and Mallery's (2003) thumb rule provides the Cronbach's alpha coefficient greater than '0.6' will come under an acceptable zone. In this experiment, My Cronbach's alpha coefficient is ' 0.64 '. In conclusion, I am confident that my scale measurement is standardized and related to a set of variables are as a group.

\section{Multiple correlations between variables}

A multiple correlation analysis illustrates a linear relationship between the dependent and independent variables value ranging from -1 to +1 . The correlation coefficient closer to +1 is considered a strong relationship between variables. Table 2 presents mean, standard deviation, and inter-correlations among variables to examine the reaction of independent variables (employee engagement, diversity training, diversity alignment \& mutual respect) on the dependent variable (diversity awareness).

Table 2-Mean, standard deviation and inter-correlations among variables

\begin{tabular}{|c|c|c|c|c|c|c|c|}
\hline & $\begin{array}{l}\text { Me } \\
\text { an }\end{array}$ & $\begin{array}{l}\text { Std. } \\
\text { devia } \\
\text { tion }\end{array}$ & $\begin{array}{c}\text { Diversi } \\
\text { ty } \\
\text { aware } \\
\text { ness } \\
\end{array}$ & $\begin{array}{c}\text { Employee } \\
\text { engagem } \\
\text { ent }\end{array}$ & \begin{tabular}{|c} 
Divers \\
ity \\
traini \\
$n g$ \\
\end{tabular} & $\begin{array}{c}\text { Divers } \\
\text { ity } \\
\text { align } \\
\text { ment } \\
\end{array}$ & $\begin{array}{c}\text { Mutual } \\
\text { respect }\end{array}$ \\
\hline $\begin{array}{c}\text { Diversit } \\
y \\
\text { awaren } \\
\text { ess }\end{array}$ & $\begin{array}{c}3.5 \\
6\end{array}$ & 1.47 & 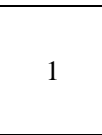 & & & & \\
\hline $\begin{array}{c}\text { Employ } \\
\text { ee } \\
\text { engage } \\
\text { ment } \\
\end{array}$ & $\begin{array}{c}2.9 \\
6\end{array}$ & 1.17 & $0.43^{*}$ & 1 & & & \\
\hline $\begin{array}{c}\text { Diversit } \\
y \\
\text { training }\end{array}$ & $\begin{array}{c}2.9 \\
8\end{array}$ & 1.04 & $0.52^{*}$ & 0.18 & 1 & & \\
\hline $\begin{array}{c}\text { Diversit } \\
y \\
\text { alignme } \\
n t \\
\end{array}$ & $\begin{array}{c}3.4 \\
3\end{array}$ & 1.24 & $0.62^{*}$ & 0.25 & 0.62 & 1 & \\
\hline $\begin{array}{l}\text { Mutual } \\
\text { respect }\end{array}$ & $\begin{array}{c}3.3 \\
3\end{array}$ & 1.13 & $\begin{array}{c}0.02 * \\
*\end{array}$ & 0.09 & -0.03 & -0.11 & 1 \\
\hline
\end{tabular}

Note: $* p<0.05 \quad * * p>0.05$

Table 2 shows the correlation coefficient between diversity awareness and employee engagement $(r=0.43)$, diversity awareness and diversity training $(r=0.52)$, diversity awareness and diversity alignment $(r=0.62)$, which is a statistically significant positive relationship $(p<0.05)$. The correlation coefficient between mutual respect and diversity awareness ( $r=-0.02)$ showed a negative relationship and statistically not significant $(p>0.05)$ (please see table-2). The literature supported that respect differs from person to person (Spagnoletti \& Arnold, 2007). Bangladesh is a nation where a wide range of population resides with diverse religions, traditions, faiths, backgrounds, cultures, and languages. The Bangladeshis have various belief systems, and points of view that probably result in either respect are revealed indirectly to others or not understood by the next person (Worthington \& Gogne, 2011). Thus, such perceptions possibly turned the correlation test, which resulted in the absence of statistical evidence to signify the relationship between mutual respect and diversity awareness.

\section{Multiple linear regression analysis}

Multiple regression measures the extent of the dependent variable's inconsistency explained by the several independent variables or explanatory variables. In this study, multiple correlations and $\mathrm{R}^{2}$ (coefficient of determination) defined at a $5 \%$ level of significance by the multiple regression model (please see table-3).

Table 3-Multiple regression model Model summary

\begin{tabular}{|c|c|c|c|}
\hline$R$ & $\begin{array}{c}\mathrm{R} \\
\text { Square }\end{array}$ & $\begin{array}{c}\text { Adjusted } \mathrm{R} \\
\text { Square }\end{array}$ & $\begin{array}{c}\text { Std. error of the } \\
\text { estimate }\end{array}$ \\
\hline $0.701^{\mathrm{a}}$ & 0.492 & 0.482 & 1.057 \\
\hline
\end{tabular}

a. Predictors: (constant), employee engagement, diversity training, diversity alignment \& mutual respect.

b. Dependent variable: diversity awareness.

Source: Developed from the research

According to the model summary above, the $\mathrm{R}$ square value is 0.492. It means that $49.2 \%$ of the diversity awareness explained by the independent variables, i.e., employee engagement, diversity training, diversity alignment, and mutual respect in this research. I can conclude that other potential factors explain $29.9 \%(100 \%-70.1 \%)$ of diversity awareness. The adjusted $\mathrm{R}$ square value is 0.482 , which means $48.2 \%$ of the variation in the diversity awareness explained by these four independent variables in a model (please see table-3).

\section{Multiple regression analysis}

Table 4-Multiple regression coefficient analysis Coefficients

\begin{tabular}{|l|l|l|l|l|l|l|}
\hline & $\begin{array}{l}\text { Coefficients } \\
(\beta)\end{array}$ & $\begin{array}{l}\text { Standard } \\
\text { Error }\end{array}$ & t Stat & P-value & $\begin{array}{l}\text { Lower } \\
95 \%\end{array}$ & $\begin{array}{l}\text { Upper } \\
95 \%\end{array}$ \\
\hline Intercept & -0.138 & 0.345 & $\begin{array}{l}- \\
0.400\end{array}$ & 0.6893 & -0.819 & 0.543 \\
\hline $\begin{array}{l}\text { Employee } \\
\text { engagement }\end{array}$ & 0.361 & 0.064 & 5.653 & $5.02 \mathrm{E}-08$ & 0.235 & 0.487 \\
\hline $\begin{array}{l}\text { Diversity } \\
\text { training }\end{array}$ & 0.312 & 0.088 & 3.553 & 0.000468 & 0.139 & 0.486 \\
\hline $\begin{array}{l}\text { Diversity } \\
\text { alignment }\end{array}$ & 0.484 & 0.075 & 6.431 & $8.21 \mathrm{E}-10$ & 0.335 & 0.632 \\
\hline $\begin{array}{l}\text { Mutual } \\
\text { respect }\end{array}$ & 0.011 & 0.065 & 0.164 & 0.8701 & -0.117 & 0.138 \\
\hline
\end{tabular}

a. Dependent variable: diversity awareness.

Source: Developed from the research.

Multiple Regression equation:

$$
\mathrm{Y}=\mathrm{C}+\beta \mathrm{X}_{1}+\beta \mathrm{X}_{2}+\beta \mathrm{X}_{3}+\beta \mathrm{X}_{4}+\ldots \ldots+\beta \mathrm{Xn}
$$

where, 
$Y=$ Prediction relationship of types of variables towards diversity awareness

$$
\begin{aligned}
& C=\text { Constant value } \\
& \beta=\text { Coefficients }
\end{aligned}
$$

$\mathrm{X}=$ Dimension of the independent variables (employee engagement, diversity training, diversity alignment, and mutual respect)

From Table 4, I derived the following equation;

$$
\mathrm{Y}=-0.138+0.361 \mathrm{X}_{1}+0.312 \mathrm{X}_{2}+0.484 \mathrm{X}_{3}+0.011 \mathrm{X}_{\mathbf{4}}
$$

Table 4 interprets that the increase of 1 unit of employee engagement (X1) will result in a rise of $22.3 \%$ ($0.138+0.361)$ in the employees' diversity awareness (Y). Further, for the independent variable of diversity training, every 1 unit of increase will rise by $17.4 \%(-0.138+0.312)$ in the dependent variable, i.e., the diversity awareness of employees. The 1-unit increase in the diversity alignment may cause a $34.6 \%(-0.138+0.484)$ increase in employees' diversity awareness. On the other hand, the 1-unit increase in mutual respect inversely affects the employees' diversity awareness. The highest beta $(\beta)$ value of any independent variable is evidence of becoming the most significant variable towards the dependent variable. Table 4 shows that the diversity alignment (independent variable) has the highest positive beta $(\beta)$ value of 0.484 . It means that diversity alignment has contributed the most and has a more substantial effect on the employees' diversity awareness than other independent variables (please see table-4).

\section{ANOVA: Single-factor}

Professor R. A. Fisher first used the term 'variance.' He developed a theory on 'ANOVA' explaining its procedure to test the difference among different groups of data for homogeneity. This technique used when multiple sample cases are involved. I examined the significance of the differences amongst the 5-sample means of defined variables using the ANOVA single factor technique (please see table-5).

Solutions: I desired to test;

Ho: No significant difference in the sample responses received for five defined variables.

H1: The sample responses received for five defined variables are significantly different.

The MS Excel-2016 produced the following results given in Table 5;

Table 5-Analysis of variance for one-way ANOVA

\begin{tabular}{|c|c|c|c|c|c|c|}
\hline $\begin{array}{c}\text { Source } \\
\text { of } \\
\text { variation }\end{array}$ & $\begin{array}{c}\text { Sum of } \\
\text { squares } \\
\text { (SS) }\end{array}$ & df & $\begin{array}{c}\text { Mean } \\
\text { sum of } \\
\text { square } \\
\text { s (MS) }\end{array}$ & F-ratio & $\begin{array}{c}\text { P- } \\
\text { value }\end{array}$ & $\begin{array}{c}\text { F } \\
\text { crit. }\end{array}$ \\
\hline $\begin{array}{c}\text { Between } \\
\text { Groups }\end{array}$ & 64.701 & 4 & 16.175 & 10.901 & $\begin{array}{c}1.14 \mathrm{E}- \\
08\end{array}$ & 2.380 \\
\hline
\end{tabular}

\begin{tabular}{|c|c|c|c|c|c|c|}
\hline $\begin{array}{c}\text { Within } \\
\text { Groups }\end{array}$ & 1609.913 & 1085 & 1.484 & & & \\
\hline Total & 1674.614 & 1089 & & & & \\
\hline
\end{tabular}

Table 5 shows that the calculated value of F-ratio is 10.901 , which is higher than the critical value of F-distribution 2.380 at a 5\% significance level with a degree of freedom (df) V1 = 4 and V2 $=1085$. Hence, I reject the null hypothesis at $5 \%$ level of significance (please see table-5).

Table 6-Summary for one-way ANOVA

\begin{tabular}{|l|l|l|l|l|}
\hline Groups & Count & Sum & Average & Variance \\
\hline Diversity awareness & 218 & 774 & 3.550 & 2.156 \\
\hline $\begin{array}{l}\text { Employee } \\
\text { engagement }\end{array}$ & 218 & 643 & 2.950 & 1.366 \\
\hline Diversity training & 218 & 648 & 2.972 & 1.078 \\
\hline Diversity alignment & 218 & 748 & 3.431 & 1.546 \\
\hline Mutual respect & 218 & 726 & 3.330 & 1.273 \\
\hline
\end{tabular}

After rejecting the null hypothesis, I would like to know which pairs are different. To understand this, I obtained the critical differences for each pair of treatments.

I can see that sample size, $\mathrm{n}_{1}=\mathrm{n}_{2}=\mathrm{n}_{3}=\mathrm{n}_{4}=\mathrm{n}_{5}=218, \mathrm{k}$ (number of treatments) $=5, \mathrm{MS}$ within groups $=1.484$, and $\mathrm{F}$ critical value at $5 \%$ level is 2.380 . Since all sample sizes are same, therefore all critical differences will be same, given as;

$$
\begin{aligned}
& =\sqrt{ }\left[\mathrm{MS} \text { within groups }\left(1 / \mathrm{n}_{\mathrm{i}}+1 / \mathrm{n}_{\mathrm{j}}\right) \times(\mathrm{k}-1) \times \mathrm{F}_{\mathrm{k}-1, \mathrm{n}-\mathrm{k}, \alpha}\right] \\
& =\sqrt{ }[1.484(1 / 218+1 / 218) \times(5-1) \times 2.380] \\
& =\sqrt{ } 0.1296 \\
& =0.36
\end{aligned}
$$

\begin{tabular}{|c|c|c|c|}
\hline $\begin{array}{l}\text { Pair of } \\
\text { treatments }\end{array}$ & $\begin{array}{c}\text { The } \\
\text { difference } \\
\text { in sample } \\
\text { means }\end{array}$ & $\begin{array}{c}\text { Critical } \\
\text { difference }\end{array}$ & $\begin{array}{c}\text { Conclusion at } 5 \% \text { level of } \\
\text { significance }\end{array}$ \\
\hline $\begin{array}{c}\text { Diversity } \\
\text { awareness and } \\
\text { employee } \\
\text { engagement }\end{array}$ & 0.6 & 0.36 & $\begin{array}{c}\text { Diversity awareness and } \\
\text { employee engagement differ } \\
\text { significantly }\end{array}$ \\
\hline $\begin{array}{c}\text { Employee } \\
\text { engagement and } \\
\text { diversity } \\
\text { training } \\
\end{array}$ & 0.022 & 0.36 & $\begin{array}{c}\text { Employee engagement and } \\
\text { diversity training differ } \\
\text { significantly }\end{array}$ \\
\hline $\begin{array}{l}\text { Diversity } \\
\text { training and } \\
\text { diversity } \\
\text { alignment } \\
\end{array}$ & 0.459 & 0.36 & $\begin{array}{c}\text { Diversity training and } \\
\text { diversity alignment differ } \\
\text { significantly }\end{array}$ \\
\hline $\begin{array}{c}\text { Diversity } \\
\text { alignment and }\end{array}$ & 0.101 & 0.36 & $\begin{array}{l}\text { Diversity alignment and } \\
\text { mutual respect differ }\end{array}$ \\
\hline
\end{tabular}

Sample means for variables, i.e., diversity awareness, employee engagement, diversity training, diversity alignment, and mutual respect, are 3.550, 2.950, 2.972, 3.431, and 3.330, respectively. I make the table below for each pair of treatments (please see table-7):

Table 7-Pair of treatments 


\begin{tabular}{|c|c|c|c|}
\hline mutual respect & & & significantly \\
\hline $\begin{array}{c}\text { Mutual respect } \\
\text { and diversity } \\
\text { awareness }\end{array}$ & 0.22 & 0.36 & $\begin{array}{c}\text { Mutual respect and diversity } \\
\text { awareness differ } \\
\text { significantly. }\end{array}$ \\
\hline
\end{tabular}

Thus, I conclude that all groups identified (defined) variables have a different effect on the response of the target population (employees).

Figure 2-Final conceptual framework representing correlation coefficient and p-value significance

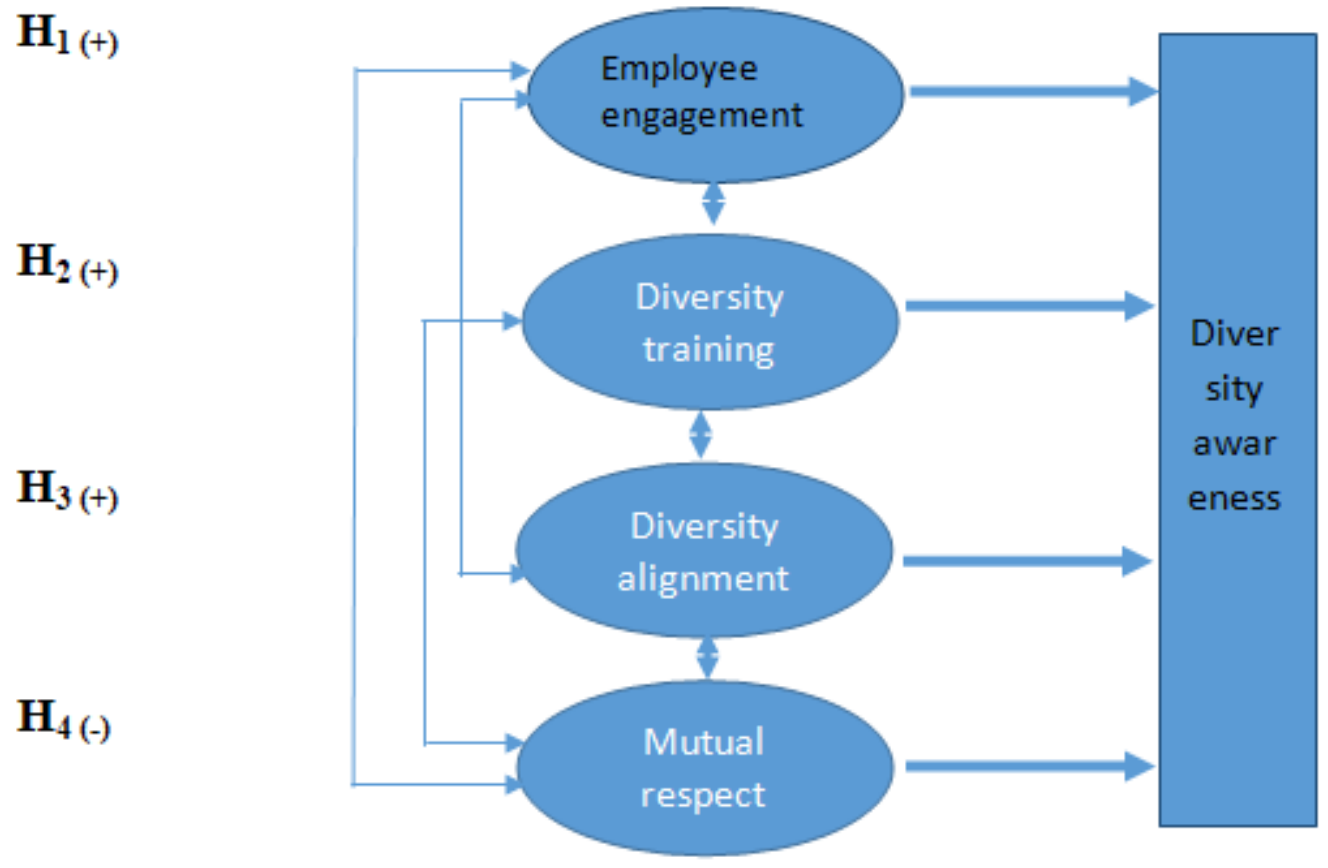

Notes: *significant at $p$-value $<.05, * *$ non-significant at $p$-value $>.05$

The bold numerical value represents the correlations coefficient between independent variables (please see figure-2).

The empirical test of independent variables shows a positive relationship, employee engagement and diversity training $(r=$ $0.18)$, employee engagement and diversity alignment $(r=$ $0.25)$, employee engagement and mutual respect $(r=0.09)$, diversity training and diversity alignment $(r=0.62)$ which is a strong positive relationship. A negative relationship between diversity alignment and mutual respect $(r=-0.11)$, diversity training, and mutual respect $(r=-0.03)$ reported in the empirical test. My research findings proved that there is a positive significant relationship between diversity awareness and employee engagement $(r=0.43, p=5.02 \mathrm{E}-08<0.05)$, diversity awareness and diversity training $(\mathrm{r}=0.52, p=$ $0.0005<0.05)$, diversity awareness and diversity alignment $(r=0.62, p=8.21 \mathrm{E}-10<0.05)$. Diversity awareness and mutual respect $(r=-0.02, p=0.8701>0.05)$ reported an opposite and nonsignificant relationship. In a nutshell, the theoretical framework suggests that how employee engagement, diversity training, diversity alignment, and mutual respect can be related to becoming significant factors to predict the degree of diversity awareness of diverse employees employed in Bangladeshi origin organizations. The results of the hypothesis test discussed below (please see table-8).

\section{DISCUSSION OF MAJOR FINDINGS}

Table 8-Summary of results

\begin{tabular}{|c|c|c|}
\hline Hypotheses & Results & $\begin{array}{c}\text { Supported } \\
\text { (Yes/No })\end{array}$ \\
\hline $\begin{array}{c}\text { H1: There is a significant positive } \\
\text { relationship between diversity awareness } \\
\text { and employee engagement. }\end{array}$ & $\begin{array}{c}\mathrm{r}=0.43 \\
(\mathrm{p}<0.05)\end{array}$ & Yes \\
\hline $\begin{array}{c}\text { H2: There is a significant positive } \\
\text { relationship between diversity awareness } \\
\text { and diversity training. }\end{array}$ & $\begin{array}{c}\mathrm{r}=0.52 \\
(\mathrm{p}<0.005)\end{array}$ & Yes \\
\hline $\begin{array}{c}\text { H3: There is a significant positive } \\
\text { relationship between diversity awareness } \\
\text { and diversity alignment. }\end{array}$ & $\begin{array}{c}\mathrm{p}=0.62 \\
(\mathrm{p}<0.05)\end{array}$ & Yes \\
\hline $\begin{array}{c}\text { H4: There is a non-significant negative } \\
\text { relationship between diversity awareness } \\
\text { and mutual respect. }\end{array}$ & $\begin{array}{c}\mathrm{r}=-0.02 \\
\mathrm{p}=0.8701\end{array}$ & No \\
\hline
\end{tabular}

H1: There is a significant positive relationship between diversity awareness and employee engagement.

The hypothesis test showed a significantly positive relationship between employee engagement (independent 
variable) and diversity awareness (dependent variable). The value of 0.43 indicates that employee engagement positively correlated to diversity awareness. Thus, $\mathrm{p}=5.02 \mathrm{E}-08(\mathrm{p}<0.05)$. Hence, $\mathrm{H} 1$ is supported (please see table-8).

Several psychological studies showed that diversity and inclusion influence cognitive, spiritual, mental, emotional, and social developments within groups (e.g., Kearney et al., 2009; Pendry et al., 2007; Stockdale \& Crosby, 2004; Hobman et al., 2003). Itam and Bagali (2018) found that organizations with a sensible leadership team emphasize performance relative to individual differences such as educational qualification, background, age, gender, ethnicity, or sexual orientation. It directs towards the ignorance of all such variations, and an individual shows the utmost commitment for improved performance. It increases a firm's competitiveness and diversity awareness (Itam \& Bagali, 2018). The research proved that an engaged workforce is psychologically committed to improving organizational performance, effectiveness, and efficiency regardless of inter-cultural differences (Ferry, 2013). It shows that employee engagement inevitably minimizes differences and motivate groups to offer views and accept one another applicable perspectives, opinions, and ideas. Honoring other's perceptions itself symbolizes the awareness of diversity inclusiveness. Eventually, my study also proved that employee engagement enhances the degree of diversity awareness of diverse employees working in Bangladeshi origin firms.

H2: There is a significant positive relationship between diversity awareness and diversity training.

The hypothesis test proved that there is a significant positive relationship between diversity training (independent variable) and diversity awareness (dependent variable). The value of 0.52 indicates that diversity training positively correlated to diversity awareness. Thus, $\mathrm{p}=0.0005(\mathrm{p}<0.05)$. Hence, $\mathrm{H} 2$ is supported (please see table-8).

Numerous studies and literature have shown that diversity training is a useful tool to disseminate cultural sensitivity and consciousness among varied employees (e.g., Bezrukova, Jehn, \& Spell, 2012; Roberson, Kulik, \& Pepper, 2001). Diversity training is a cross-cultural sensitivity activity that aims to facilitate positive intergroup interactions, reduces prejudice and discrimination, and enhances the skills, knowledge, and motivation of people to interact with others (Bezrukova et al., 2012, p. 208). The literature supported that diversity training increases diversity awareness (Kalinoski et al., 2012; Bezrukova et al., 2012). However, the features of diversity training initiatives are less valued (Pendry, Driscoll \& Field, 2007). Diversity awareness can be a crucial characteristic of diversity training activity to make diverse employees sensitized by exchanging beliefs, ethos, norms, traits, and avoiding biases. In conclusion, the hypothesis test successfully proved that diversity training is a fundamental consideration for the improvement of diversity awareness of diverse employees working in Bangladeshi origin firms.
H3: There is a significant positive relationship between diversity awareness and diversity alignment.

The hypothesis test showed a significantly positive relationship between diversity alignment (independent variable) and diversity awareness (dependent variable). The value of 0.62 indicates that the diversity alignment positively correlated to the diversity awareness, and its p-value is $8.21 \mathrm{E}$ $10(\mathrm{p}<0.05)$. Hence, H3 is supported (please see table-8).

In this research, diversity alignment refers to inclusiveness. The alignment of corporate culture, process, and diversity of employees offer a workplace atmosphere of respect, multifacet aspects, and opportunity. It leverages diverse perspectives and experiences to improve performance (Woods, 2002). Several studies showed that individuals in different teams are more focused on accomplishing the company's goals. They overlook bias and preconception to solve complicated problems (e.g., Nair \& Vohra, 2015; Bilimoria, Joy, \& Liang, 2008; Roberson, 2006; Leonard, Levine, \& Joshi, 2004). Eventually, My research findings proved that if diverse employees align with the organizational goals, their inter-personal understanding increases. Subsequently, it leads to appreciating diversity among themselves. Based on the evidence grounded in the literature and hypothesis test proved in this study, I conclude that diversity alignment certainly helps diverse employees increase their awareness of diversity and inclusion viewpoints.

H4: There is a non-significant negative relationship between diversity awareness and mutual respect.

The hypothesis test showed a non-significant negative relationship between mutual respect (independent variable) and diversity awareness (dependent variable). The value of 0.02 indicates that mutual respect negatively correlated to diversity awareness. Thus, $\mathrm{p}=0.8701(\mathrm{p}>0.05)$. Hence, $\mathrm{H} 4$ is not supported (please see table-8).

Eventually, mutual respect is the only independent variable that has not been supported by this study. To counter this opposing result, I carried out more examination with whatever available supporting research papers. I found that researchers have not argued much that define correlations between mutual respect and diversity awareness. However, according to Patrick and Kumar (2012), diversity awareness leads to sensible practices that include understanding and cherishing the interrelationship of diverse people, values, beliefs, qualities, experiences, and knowledge that are unique to one another. Recognizing and knowing to these uniqueness sets a pillar of mutual respect among varied employees and build alliances across differences so that a common goal could make to eliminate all forms of discrimination.

Further, literature supported that determination to accomplish shared goals bring various backgrounds employees together irrespective of differences (Patrick \& Kumar, 2012). The available literature on correlations between mutual respect and diversity awareness concludes 
that mutual respect among diverse employees boosts diversity awareness. However, I found an inverse relationship between diversity awareness and mutual respect in my experiment in Bangladeshi origin firms. I move with an offer for further research that researchers in these areas need to carry out.

\section{Managerial implications}

This paper presents specific managerial implications for human resource (HR) practitioners. In the course of applying diversity model in organizations, HR executives encounter with various issues and differences of workforces. Such things require to sort out strategically with the integration of differences. Subsequently, HR leadership has to create synergy among diverse workforces to build a culture of mutual respect. Further, the big challenge for HR practitioners is to connect shop floor (bottom of the pyramid) workforce with organizational vision. To align diverse employees with corporate objectives, HR executives need to create a positive work environment irrespective of differences in employees' age, gender, race, social, cultural, and educational background. HR practitioners usually focus on results while measuring the impact of various diversity practices. This paper suggests that HR should equally focus on finding the relationship between the diversity model and factors used to encourage cultural awareness in organizations. It gives advantages to understand whether the HR practices used for diversity awareness relates to the organizational context or not? The proposed theoretical model could help HR practitioners to correlate diversity awareness with defined variables in this study for further prediction of the effectiveness of diversity initiatives.

\section{Future research directions \& limitations}

This study possesses some limitations that deserve further research. I took a sample size of almost 50-50 percent from the male and female populations for my research. Kundu (2004) found in his study that females are generally more concerned about adopting diversity practices than males. Usually, the diversity perception of males and females differs (van de Vijver, 2007). Further, the attitudes of various groups of employees also differ significantly (Shamir $\&$ Drory, 1981). However, respondents were requested to answer the questionnaires based on their general perception and opinion towards diversity management to the extent possible. I selected respondents from four different organizations, and they may prejudice in replying to the questionnaires. The diversity and inclusion understanding of employees may be dissimilar in different organizations (Guillaume, Brodbeck, \& Riketta, 2012; Tsui \& Gutek, 1999). Probably, they tend to have a similar or different opinion on particular points of diversity practices since they are associated with divergent organizational culture. Thus, it may lead to a lack of accuracy and reliability in replying to the questionnaires. Several other aspects influence diversity awareness, except employee engagement, diversity training, diversity alignment, and mutual respect. This topic deserves further research by covering multiple organizations/broader organizational aspects with a larger sample size from various public and private firms. Diversity is an emerging HR practice that needs to be adopted strategically to make the organization a multicultural firm. In the fast-paced business environment and continuous change in the work culture, promoting diversity awareness will be vital in many Bangladeshi origin firms.

\section{CONCLUSION}

Diversity awareness is a primary objective of diversity and inclusion policy in the areas of human resource practices/industrial/organizational psychology. This paper shows the correlations of diversity awareness with employee engagement, diversity training, diversity alignment, and mutual respect in Bangladeshi origin organizations. The results highlighted that diversity awareness is, although positively correlated with three independent variables except for mutual respect. However, practically it is yet delivered to the blue-collar/clerical categories of employees. Lumadi (2008) discovered that interpersonal connection is one of the critical determinants for having diversity awareness among a varied workforce. My experiment found that mutual respect is negatively correlated with diversity awareness and not supported in the hypothesis test. It shows that employees working in Bangladeshi origin firms are somewhere having a lack of respect for one another's culture, caste, creed, religion, race, norms, and traits. Research says if people are aware of diverse perspectives, there will be a presence of mutual respect to one another and create an atmosphere where anyone can share his/her divergent ideas, opinions, views, and perspectives (Jones \& George, 2009). Further, some study also says that the dissemination of diversity awareness initiative needs to be taken by top leadership and showing commitment to inculcate throughout the organization to achieve its optimal results (Rahman, 2019). In conclusion, I predict that Bangladeshi origin firms will overcome the differences and aspire to be culturally, geographically, and economically diversified institutions.

\section{REFERENCES}

[1] Abidi, O., Zaim, H., Youssef, D., \& Baran, A. (2017). Diversity management and its impact on HRM practices: evidence from Kuwaiti companies. Eurasian Journal of Business and Economics, 10(20), 71-88. DOI: 10.17015/ejbe.2017.020.05.

[2] Agrawal, S. (2016). Factors influencing employee engagement: A study of the diverse workforce. available at: https://www.semanticscholar.org/paper (accessed 12 January 2020).

[3] Al-Obaydi, L.H. (2019). Cultural diversity, awareness and teaching: a study in an EFL context. Journal of Asia TEFL, 16(3), 987-995. doi:10.18823/asiatefl.2019.16.3.15.987.

[4] Alhejji, H., Garavan, T., Carbery, R., O'Brien, F., \& McGuire, D. (2016). Diversity training programme outcomes: a systematic review. Human Resource Development Quarterly, 27(1), 95-149. doi: $10.1002 / \mathrm{hrdq} .21221$

[5] Athanasopoulou et al. (2018). Claiming the corner office: female CEO careers and implications for leadership development. Human Resource Management, 57(2), 617-640. https://doi.org/10.1002/hrm.21887. 
[6] Ayega, E. N., \& Muathe, S. (2018). Critical review of literature on cultural diversity in the work place and organizational performance: a research agenda. Journal of Human Resource Management, 6(1), 9-17. doi: 10.11648/j.jhrm.20180601.12.

[7] Bader, A. K., Kemper, L. E., \& Froese, F.J. (2019). Who promotes a value-in-diversity perspective? a fuzzy set analysis of executives' individual and organizational characteristics. Human Resource Management, 58(2), 203-217. doi: 58. 10.1002/hrm.21946.

[8] Balanagalakshmi, B. \& Kumari, S.S. (2019). Employees' perception on diversity in management. International Journal of Recent Technology and Engineering, 8(1C2), 7-11, ISSN: 22773878.

[9] Baltes, B., Hernandez, D. \& Collins, C. (2015). Increasing cultural awareness through a cultural awareness program. Journal of Educational Research and Practice, 5(1), 1-20. doi: 10.5590/JERAP.2015.05.1.01.

[10] Bartlett, K.R. (2001). The relationship between training and organizational commitment: a study in the health care field. Human Resource Development Quarterly, 12(4), 335-352.

[11] Bertrand, M., \& Mullainathan, S. (2004). Are Emily and Greg more employable than Lakisha and Jamal? a field experiment on labor market discrimination. The American Economic Review, 94(4), 991-1013.

[12] Bezrukova, K., Jehn, K. \& Spell, C. S. (2012). Reviewing diversity training: where we have been and where we should go. Academy of Management Learning \& Education, 11(2), 207227. doi: 10.5465/amle.2008.0090.

[13] Birkelund, G. E., Johannessen, L. E. F., Rasmussen, E. B., \& Rogstad, J. (2020). Experience, stereotypes and discrimination employers' reflections on their hiring behavior. European Societies. doi: 10.1080/14616696.2020.1775273.

[14] Buckingham, M. \& Coffman, C. (1999). First, break all the rules: What the world's greatest managers do differently. New York, NY.: Simon \& Schuster.

[15] Caiani, T.S.P. (2015). Examination of employee alignment as a predictor of work engagement. Master's Theses, 4554, available at: https://doi.org/10.31979/etd.ydep-ks65 (accessed 23 $2{ }^{\text {rd }}$ March 2020).

[16] Cappelli, P. (1999). The new deal at work: managing the marketdriven workforce. Boston, MA: Harvard Business School Press.

[17] Cavaleros, C., Vuuren, L.J.V. \& Visser, D. (2002). The effectiveness of a diversity awareness training programme. $S A$ Journal of Industrial Psychology, 28(3), 50-61. doi: 10.4102/sajip. v28i3.6.

[18] Chandani, A., Mehta, M., Mall, A. \& Khokhar, V. (2016). Employee engagement: A review paper on factors affecting employee engagement. Bangladesh Journal of Science and Technology, 9 (15), 1-7. doi: 10.17485/ijst/2016/v9i1 S5/92145.

[19] Chattopadhyay, P., George, E., \& Shulman, A. D. (2008). The asymmetrical influence of sex dissimilarity in distributive vs. collocated work groups. Organization Science, 19(4), 581-593.

[20] Chomeya, R. (2010). Quality of psychology test between Likert scale 5 and 6 points. Journal of Social Sciences, 6(3), 399-403.

[21] Chuang, S. F. (2013). Essential skills for leadership effectiveness in diverse workplace development. Online Journal for Workforce Education and Development, 6(1). available at: https://opensiuc.lib.siu.edu/ojwed/vol6/iss1/5/.

[22] Cooke, F.L. \& Saini, D.S. (2010). Diversity management in Bangladesh: A study of organizations in different ownership forms and industrial sectors. Human Resource Management, 49(3), 477 500 .

[23] Dickert, N.W. \& Kass, N.E. (2009). Understanding respect: learning from patients. Journal of Medical Ethics, 35(7), 419-423. doi: https://doi.org/10.1136/jme.2008.027235.

[24] Downey, S. N., Werff, L.V.D, Thomas, K.M. \& Plaut, V.C (2015). The role of diversity practices and inclusion in promoting trust and employee engagement. Journal of Applied Social Psychology, 45(1), 35-44.
[25] Duchek, S., Raetze, S. \& Scheuch, I. (2019). The role of diversity in organizational resilience: A theoretical framework. Business Research. doi: https://doi.org/10.1007/s40685-019-0084-8.

[26] Enga, E. (2017). The impact of training and development on organizational performance. National Financial Bank Kumba Case Study, Centria University of Applied Sciences Publishing. available

at: https://www.theseus.fi/bitstream/handle/10024/133220/Engeto u\%20Enga.pdf? (accessed 20 February 2020).

[27] Ferguson, E. D. \& Page, L. J. (Eds.) (2003). Work relationships, lifestyle, and mutual respect. The Journal of Individual Psychology, 59(4), 501-506.

[28] Findler L., Wind, L. H., \& Barak, M. E. M. (2007). The challenge of workforce management in a global society: modeling the relationship between diversity, inclusion, organizational culture, and employee well-being, job satisfaction and organizational commitment. Administration in Social Work, 31(3), 63-94.

[29] Friedman, H. H., Leverton, C., \& Friedman, L. W. (2015). To foster creativity and success, remove intentional and unintentional discrimination. SSRN Electronic Journal. available at: https://ssrn.com/abstract=2649712 http://dx.doi.org/10.2139/ssrn.2649712 (accessed 12 March 2020).

[30] Goldberg, C. B. (2005). Relational demography and similarityattraction in interview assessments and subsequent offer decisions: are we missing something? Group \& Organization Management, 30(6), 597-624.

[31] Gruman, J. A. \& Saks, A.M. (2011). Performance management and employee engagement. Human Resource Management Review, 21(2), 123-136. doi: 10.1016/j.hrmr.2010.09.004.

[32] Guillaume, Y. R. F., Brodbeck, F. C., \& Riketta, M. (2012). Surface and deep level dissimilarity effects on social integration and individual effectiveness related outcomes in work groups: a meta-analytic integration. Journal of Occupational and Organizational Psychology, 85, 80-115. doi: 10.1111/j.20448325.2010.02005.x.

[33] Hansson, M. \& Wigblad, R. (2006). Recontextualizing the Hawthorne effect. Scandinavian Journal of Management, 22 (2), 120-137. doi: 10.1016/j.scaman.2005.12.003.

[34] Harrison, D. A., Price, K. H., \& Bell, M. P. (1998). Beyond relational demography: time and the effects of surface- and deeplevel diversity on work group cohesion. Academy of Management Journal, 41(1), 96-107.

[35] Horwitz, S.K., \& Horwitz, I.B. (2007). The effects of team diversity on team outcomes: a meta analytic review of team demography. Journal of Management, 33(6), 987-1015.

[36] Howard, A. (Ed.). (1995). The changing nature of work. San Francisco, CA: Jossey-Bass Publishers.

[37] Ilgen, D. R., \& Pulakos, E. D. (Eds.). (1999). The changing nature of performance: implications for staffing, motivation, and development. San Francisco, CA: Jossey-Bass Publishers.

[38] Imandin, L., Bisschoff, C. \& Botha, C. (2014). A model to measure employee engagement. Problems and Perspectives in Management, 12(4), 520-532.

[39] Itam, U. \& Bagali, M.M. (2018). Diversity and inclusion management: a focus on employee engagement. In Diversity and Inclusion Management (chap. 93, pp. 1771-1788). doi: 10.4018/978-1-5225-6912-1.ch093.

[40] James, J. B., Mckechnie, S., \& Swanberg, J. (2010). Predicting employee engagement in an age-diverse retail workforce. Journal of Organizational Behaviour, 32(2), 173-196. doi: $10.1002 /$ job.681.

[41] Jawale, K.V. (2016). Issues and challenges of LGBT minority people in Bangladesh. International Journal of Applied Research, 2(6), 408-410.

[42] Jehanzeb, K., \& Bashir, N.A. (2013). Training and development program and its benefits to employee and organization: a conceptual Study. European Journal of Business and Management, 5(2), 243-252.

[43] Joshi, A., Kale, S., Chandel, S., \& Pal, D. (2015). Likert scale: explored and explained. British Journal of Applied Science \& Technology, 7(4), 396-403. doi: 10.9734/BJAST/2015/14975. 
[44] Kaufman, J. C., Baer, J. Agars, M. D., \& Loomis, D. (2010). Creativity stereotypes and the consensual assessment technique. Creativity Research Journal, 22(2), 200-205.

[45] Khan, R.A.G., Khan, F.A., \& Khan, M.F. (2011). Impact of training and development on organizational performance. Global Journal of Management and Business Research, 11(7), 62-67.

[46] Korte, R. F. (2007). A review of social identity theory with implications for training and development. Journal of European Industrial Training, 31(3), 166-180.

[47] Kundu, S.C. (2003). Workforce diversity status: A study of employees' reactions. Industrial Management \& Data Systems, 103(4), 215-226. doi: 10.1108/02635570310470610.

[48] Kundu, S.C. (2004). H.R. diversity: A study of employees' perceptions in Bangladeshi organizations. Asia Pacific Management Review, 9(1), 39-59.

[49] Kundu, S.C., Bansal, J., Mor, A., \& Pruthi, M. (2018). Workforce diversity status in Bangladeshi public sector: A study of employees' reactions. Journal of Organization \& Human Behaviour, 7(2 \& 3), 34-46.

[50] Kutch, B.D.M., \& Kutch, J.S.M. (2019). Innovation through diversity and inclusion: In A Roadmap for Higher Education Information Technology lead ers (pp. 49-78). doi: 10.4018/978-1-5225-7769-0.ch003.

[51] Lee, P.M., \& James, E.H. (2007). She'-e-os: gender effects and investor reactions to the announcements of top executive appointments. Strategic Management Journal, 28(3), 227-241.

[52] Macey, W. H. \& Schneider, B. (2008). The meaning of employee engagement. Industrial and Organizational Psychology, 1(1), 330. doi: 10.1111/j.1754-9434.2007. 0002.x.

[53] Mazur, B. (2014). Building diverse and inclusive organizational culture-best practices: a case study of Cisco Co. Journal of Intercultural Management, 6(4), 169-179. doi: 10.2478/joim2014-0043.

[54] Meena, K. (2015). Diversity dimensions of Bangladesh and their organization challenges: an analysis. IOSR Journal of Business and Management, 17(7), 77-90.

[55] Miller, C. C., Burke, L. M., \& Glick, W. H. (1998). Cognitive diversity among upper-echelon executives: implications for strategic decision processes. Strategic Management Journal, 19(1), 39-58.

[56] Nair, N. \& Vohra, N. (2015). Diversity and inclusion at the workplace: a review of research and perspectives. I.I.M.A. Working Paper No. WP2015-03-34, Bangladeshi Institute of Management Ahmedabad, Research and Publication Department. available

https://web.iima.ac.in/assets/snippets/workingpaperpdf/863146707 2015-03-34.pdf (accessed 25 February 2020).

[57] Nda, M.M. \& Fard, R.Y. (2013). The impact of employee training and development on employee productivity. Global Journal of Commerce \& Management Perspective, 2(6), 91-93. ISSN: 23197285.

[58] O'Grady, E. (2017). Learning to be more human: perspectives of respect by young Irish people in prison. Journal of Prison Education and Re-entry, 4(1), 4-16. doi: http://dx.doi.org/10.15845/jper.v4i1.1010.

[59] Ogbolu, Y., Scrandis, D., \& Fitzpatrick, G. (2017). Barriers and facilitators of care for diverse patients: nurse leader perspectives and nurse manager implications. Journal of Nursing Management, 26(1), 3-10. doi: 10.1111/jonm.12498.

[60] Okoro, E. (2012). Cross-cultural etiquette and communication in global business: toward a strategic framework for managing corporate expansion. International Journal of Business and Management, 7(16), 130 -138. doi:10.5539/ijbm.v7n16p130.

[61] Osborne, S., \& Hammoud, M. S. (2017). Effective employee engagement in the workplace. International Journal of Applied Management and Technology, 16(1), 50-67. doi:10.5590/IJAMT.2017.16.1.04.

[62] Patrick, H.A., \& Kumar, V.R. (2012). Managing workplace diversity: Issues and challenges. SAGE Open, 2(2), 1-15. doi: $10.1177 / 2158244012444615$.
[63] Praveenadevi, D., \& Girimurugan, B. (2019). Inclusive organizational culture - A competing strategy for business success. International Journal of Recent Technology and Engineering, 8(4), 5155-5159. doi: 10.35940/ijrte. D7371.118419.

[64] Pendry, L. F., Driscoll, D. M., \& Field, S. C. T. (2007). Diversity training: Putting theory into practice. Journal of Occupational and Organizational Psychology, 80(1), 27-50.

[65] Rahman, U.H.F.B. (2019). Diversity management and the role of leader. Open Economics, 2(1), 30-39. doi: 10.1515/openec-20190003.

[66] Reich, T., \& Hershcovis, S. (2011). Interpersonal relationships at work. In book: Handbook of Industrial and Organizational Psychology (Vol. 3, pp.223-248), Publisher: American Psychological Association, Editors: S. Zedeck, H. Aguinis, W. Cascio, M. Gelfand, K. Leung, S. Parker, J. Zhou. doi: 10.1037/12171-006.

[67] Roberson, L., Kulik, C. T. \& Pepper, M. B. (2001). Designing effective diversity training: influence of group composition and trainee experience. Journal of Organizational Behaviour, 22(8), 871-885. doi: https://doi.org/10.1002/job.117.

[68] Rodriguez, M.T. \& Lamm, A.J. (2016). Identifying student cultural awareness and perceptions of different cultures. Journal of Agricultural Education, 57(2), 106-118. doi: 10.5032/jae.2016.021061.

[69] Rogelberg, S. G. (Ed.). (2009). CEOs and human resource executives can develop talented women $\left(1^{\text {st }}\right.$ ed.). New York, NY: Wiley.

[70] Rooth, D.O. (2010). Automatic associations and discrimination in hiring: real world evidence. Labour Economics, 17(3), 523-534.

[71] Ross, D.G. \& Parks, M. (2018). Mutual respect in an ethic of care: A collaborative essay on power, trust, and stereotyping. Teaching Ethics, 18(1), 1-15. doi: 10.5840/tej2018112156.

[72] Saks, A.M. (2006). Antecedents and consequences of employee engagement. Journal of Managerial Psychology, 21(7), 600-619. doi: $10.1108 / 02683940610690169$.

[73] Salah, M.R.A. (2016). The impact of training and development on employees' performance and productivity. International Journal of Management Sciences and Business Research, 5(7), 36-70. ISSN:2226-8235.

[74] Sarangi, P. \& Nayak, B. (2016). Employee engagement and its impact on organizational success - a study in manufacturing company, Bangladesh. IOSR Journal of Business and Management, 18(4), 52-57. doi: 10.9790/487X-1804015257.

[75] Sarhan, A. A., Ntim, C. G., \& Al-Najjar, B. (2018). Board diversity, corporate governance, corporate performance and executive pay. International Journal of Finance \& Economics, 24(2), 761-786. doi: 10.1002/ijfe.1690.

[76] Schneider, B., White, S. S., \& Paul, M. C. (1998). Linking service climate and customer perceptions of service quality: test of a causal model. Journal of Applied Psychology, 83(2), 150-163. doi: 10.1037/0021-9010.83.2.150.

[77] Serin, H. (2017). Teaching about respect and tolerance with presentations on cultural values. International Journal of Social Sciences \& Educational Studies, 3(4), 174-176. doi: $10.23918 /$ ijsses. v3i4p174.

[78] Shaban, A. (2016). Managing and leading a diverse workforce: One of the main challenges in management. Procedia - Social and Behavioural Sciences, 230, 76-84. doi: 10.1016/j.sbspro.2016.09.010.

[79] Sharma, A. (2016). Managing diversity and equality in the workplace. Cogent Business \& Management, 3(1), 1-14, doi: 10.1080/23311975.2016.1212682.

[80] Shore, L.M., Randel, A.E., Chung, B.G. \& Dean, M.A. (2011). Inclusion and diversity in work groups: a review and model for future research. Journal of Management, 37(4), 2-58. doi: $10.1177 / 0149206310385943$.

[81] Siddhanta, A. \& Roy, D. (2010). Employee engagement engaging the $21^{\text {st }}$ century workforce. Asian Journal of Management Research, 170-189. available at: http://www.ipublishing.co.in/ajmrvol1no1/sped12011/AJMRSP10 15.pdf (accessed 30 March 2020). 
[82] Smith et al. (2001). An overview of diversity awareness. Ohio State University Extension. available at: http:// www.ag.ohiostate.edu/ ohiolline/bc-fact/0014.html (accessed 20 January 2020).

[83] Smilansky, J. (Ed.). (2012). Talent management and diversity. In Developing Executive Talent: $\quad$ Best Practices from Global Leaders (chap. $\quad 12, \quad$ pp. 203-215). doi:10.1002/9781119202370.ch12.

[84] Spagnoletti, C. L., \& Arnold, R. M. (2007). R-E-S-P-E-C-T: Even more difficult to teach than to define. Journal of General Internal Medicine, 22(5), 707-709. doi: https://doi.org/10.1007/s11606007-0164-x.

[85] Sun, L., \& Bunchapattanasakda, C. (2019). Employee engagement: a literature review. International Journal of Human Resource Studies, 9(1), 63-80. doi: 10.5296/ijhrs. v9i1.14167.

[86] Swartz, T.H., Palermo, A.G.S., Masur, S.K., \& Aberg, J.A. (2019). The science and value of diversity: closing the gaps in our understanding of inclusion and diversity. The Journal of Infectious Diseases, 220(S2), S33-41. doi: 10.1093/infdis/jiz174.

[87] Tahir, N., Yousafzai, I.K., Jan, S., \& Hashim, M. (2014). The impact of training and development on employees' performance and productivity: A case study of United Bank Limited Peshawar City, KPK, Pakistan. International Journal of Academic Research in Business and Social Sciences, 4(4), 86-98. doi: 10.6007/IJARBSS/v4-i4/756.

[88] Tamunomiebi, M. D., \& Dienye, M. (2019). Workforce diversity: the need for organizational paradigm shift. International Journal of Education and Management Engineering, 5(12), 1-13.

[89] Tan, T.Q. (2019). Principles of inclusion, diversity, access, and equity. The Journal of Infectious Diseases, 220(S2), S30-S32. doi: https://doi.org/10.1093/infdis/jiz198.

[90] Tienda, M. (2013). Diversity inclusion: promoting integration in higher education. Educational Researcher, 42(9), 467-475. doi: https://doi.org/10.3102/0013189X13516164.
[91] Thakur, P. (2014). A research paper on the effect of employee engagement on job satisfaction in IT sector. Journal of Business Management \& Social Sciences Research, 3(5), 31-39. ISSN No: 2319-5614.

[92] Truitt, D.L. (2011). The effect of training and development on employee attitude as it relates to training and work proficiency. SAGE Open, 1(3), 1-13. doi: 10.1177/2158244011433338.

[93] Tsui, A. S., \& Gutek, B. (1999). Demographic differences in organizations: current research and future directions. Lanham, MD: Lexington Books.

[94] Ulrich, D.A. (1998). A new mandate for human resources. Harvard Business Review, 76(1), 124-134.

[95] van de Vijver, F.J.R. (2007). Cultural and gender differences in gender-role beliefs, sharing household task and child-care responsibilities, and well-being among immigrants and majority members in the Netherlands. Sex Roles, 57, 813-824. https://doi.org/10.1007/s11199-007-9316-z.

[96] Woods, S. (2002). Creating inclusive organizations: aligning systems with diversity. Profiles in Diversity Journal, 4(1), 38-39.

[97] Worthington, R.P., \& Gogne, A. (2011). Cultural aspects of primary healthcare in Bangladesh: A case- based analysis. Asia Pacific Family Medicine, 10(8), 2-5. doi: http://www.apfmj.com/content/10/1/8.

[98] Yap, M., Holmes, M., Hannan, C.A., \& Cukier, W. (2010). The relationship between diversity training, organizational commitment, and career satisfaction. Journal of European Industrial Training, 34(6), 519-538. doi: 10.1108/03090591011061202.

[99] Zhu, D.H., \& Shen, W. (2016). Why do some outside successions fare better than others? The role of outside CEOs ' prior experience with board diversity. Strategic Management Journal, 37(13), 2695-2708. 